\title{
FISCALIDAD REAL Y RENTA FEUDAL. LA MARTINIEGA, LA FONSADERA Y EL YANTAR A MEDIADOS DEL SIGLO XIV EN LA CASTILLA DE LAS MERINDADES
}

\author{
JuLián CLEMENTE RAMOS
}

\author{
SUMARIO \\ 1. Introducción. - 2. Generalidades. - 3. La martiniega. - 4. La fonsade- \\ ra. -5 . El yantar. - 6. Las jurisdicciones. - 7. Conclusiones.
}

\section{INTRODUCCIÓN}

La fiscalidad real y la renta feudal son dos aspectos íntimamente relacionados a lo largo de toda la Edad Media tanto dentro como fuera de la Península. La frontera entre ellas es poco clara debido a que no está marcada por un fundamento doctrinal, sino que se desarrolla como una realidad fáctica; es fiscalidad lo que va al rey (algo que habría que matizar para el realengo) y renta feudal o señorial lo que perciben los señores. En muchos casos, algunas rentas se dividen o van indistintamente a uno u otro en distintos lugares. Esto no ocurre igualmente en todas ellas. La infurción, por ejemplo, es siempre una renta señorial. Sin embargo, en otras se impone el carácter ambivalente señalado. Esto es lo que nos ha llevado a elegir tres cargas -la martiniega, el yantar y la fonsadera- que, aunque en grado bastante desigual, comparten esta particularidad. Las tres han sufrido desde su origen una importante transformación hasta mediados del siglo XIV. El estudio de las mismas es fundamental para definir los límites de la renta feudal o señorial y su frontera con la fiscalidad regia. En este sentido, el Becerro de las Behetrías ofrece unas posibilidades extraordinarias, dada su riqueza informativa.

Debemos señalar además que la delimitación fiscalidąd regia/renta feudal ha sido un aspecto bastante abandonado en los estudios, por otro lado muy 
abundantes, sobre señoríos. De hecho, este campo no se aborda con el mínimo rigor, llegándose a lo sumo a generalizaciones también presentes en síntesis sobre el tema '. En este sentido, sigue siendo fundamental el estudio de C. Sánchez Albornoz sobre las inmunidades en Castilla y León hasta el siglo XIII ', pese a que no se pasa, lógico en un estudio que cuenta con más de setenta años, sino de apreciaciones cualitativas. Por tanto, el tema que abordamos esta necesitado de estudios de base que precisen el origen, naturaleza y evolución de determinadas cargas que siendo inicialmente reales pasan paulatinamente en muchos casos a ser compartidas o disfrutadas por los señores.

Hemos limitado el estudio presente a las merindades en las que el tema que nos ocupa no ha sido estudiado. Por ello, están ausentes del mismo las de la Tierra de Campos y la de Burgos-Ubierna .

\section{GENERALIDADES}

Las tres cargas que estudiamos dejan adivinar una característica importante: originariamente se integraron dentro de los derechos específicamente reales,

' Según Salvador de Moxó, Los señorios. Estudio metodológico, «I Jornadas de Metodología Aplicada de las Ciencias Históricas", II, Santiago, 1975, pp. 167-168, la martiniega al norte del Tajo y el terrazgo al sur "permiten apreciar la existencia de un señorío solariego en el sentido de existir una vinculación explícita del territorio, comprendido en el término de un señorío, con el titular de éste», lo que en todo caso sólo sería verdad muy a finales de la época medieval. Rafael GIBERT, Comunidad rural en León y Castilla durante la Edad Media, "Recueils de la Société Jean Bodin», XLIII (1984), pp. 293-295, equipara la infurción a la martiniega o la marzadga, considerando simplemente sus diferencias tipológicas al consistir la primera normalmente en especie y las otras dos en dinero. Luis García De Valdeavellano, Curso de Historia de las Instituciones Españolas, p. 251, defiende que para la renta solariega "en la baja Edad Media se generalizaron en León y Castilla los nombres de marzadga y martiniega por satisfacerse el censo en marzo o el día de San Martín"; en el mismo sentido, pero referido específicamente para el realengo, p. 600 .

2 Claudio SÁNCHez Albornoz, La potestad real y los señorios en Asturias, León y Castilla durante los siglos VIII al XIII, "Viejos y nuevos estudios sobre instituciones medievales españolas», II, Madrid, 1976, pp. 1279-1310 (la edición original de este estudio se realizó en la "Revista de Archivos, Bibliotecas y Museos» en 1914).

'Ángel VACA, La estructura socioeconómica de la Tierra de Campos a mediados del siglo XIV, «Publicaciones de la Institución Tello Tellez de Meneses», 42 (1979), pp. 203-387 (la primera parte del trabajo publicada en el número 39 aborda aspectos distintos al de las rentas señorial y real); Ignacio ALVAREZ BORGE, El feudalismo castellano y el libro Becerro de las Bebetrias, León, 1987. 
siendo en todo caso algo a matizar para el yantar ${ }^{4}$. La percepción por parte del señor aparece como un proceso posterior. Esto se adivina por dos detalles muy claros. Prácticamente sólo se señala la exención de estas rentas en relación con su cobro por el rey, pero no se hace lo mismo respecto del señor correspondiente '. Por otro lado, en el Becerro aparecen ejemplos suficientemente significativos sobre el proceso de enajenación parcial de estas rentas por parte de la realeza. Esta fuente nos deja adivinar uno de los procesos por medio del cual los señores fueron incluyendo las rentas citadas dentro de sus derechos.

El Becerro sólo nos informa de las concesiones recientes, y no de las que presumiblemente se habían consolidado desde hacía largo tiempo. En este ámbito, al margen de Pedro I o Alfonso XI, sólo se alude a Alfonso X, Sancho IV y Fernando IV ${ }^{6}$. La memoria oral en este aspecto no se remonta a mucho más de medio siglo, y esto para casos excepcionales. Sin embargo, las tenden-

4 Contamos con algunos ejemplos en los que el yantar señorial y el real parecen ser diferentes y concurrir no una sino dos cargas. En Aguilar de Campóo, «non pagan yantar (al rey) saluo si la viene y comer", y al señor, don Tello, le dan seiscientos maravedís. Más interesantes son aún los casos de Canicosa de la Sierra y Santa Inés: en el primer lugar el abad de San Pedro de Arlanza recibe su yantar en cuanto señor del lugar y «la yantar del Rey e de la Reyna e del adelantado»; en el segundo lugar también se diferencian explícitamente "la yantar del rey" y el del señor, pese a que al igual que en el lugar anterior el abad de Arlanza es el único perceptor. En Jaramillo de la Fuente y Cabezón de la Sierra los señores correspondientes reciben su yantar y una ayuda por el yantar que ellos y no los campesinos deben pagar al rey (Gonzalo MARTíNEZ DÍEZ, Libro becerro de las Bebetrias. Estudio y texto critico, 3 vols., León, 1981 (en lo sucesivo: Becerro; no señalaremos el vol. correspondiente, simplemente indicaremos un número romano y otro árabe, relativos a la merindad y al lugar respectivamente): VII, 46; XIV, 108; XV, 41, 60, 74 y 127). En Miranda y Moncalvillo, el rey recibe fonsadera, lo que no impide que el señor la obtenga también: no se habla de una carga dividida sino que se presentan dos imposiciones separadas enumeradas en los derechos reales y señoriales respectivamente. Sin embargo, para la fonsadera no puede haber duda sobre su origen real y fiscal (Becerro: XV, 66 y 68).

'En Villanueva de Carazo se indica que «Non pagan a su sennor los del dicho logar martiniegaw; la fonsadera aparece entre las exenciones dentro de los derechos señoriales en Valdenubla (Becerro: XV, 7 y XIV, 42). Frente a esto se señala en relación con los derechos reales la exención de martiniega en más de trecientas ocasiones, frente a las más de seiscientas cincuenta de la fonsadera y las casi seiscientas del yantar.

- Becerro, XIV, 7: «Este solar solia pagar por yantar e martiniega e fonsadera setenta maravedis e ocho fanegas de trigo e quatro de çevada; e dizen que lo dio el Rey don Sancho a Sancho Sanchez de Velascor e que lo dan agora de Pero Ferrandez su fiio»; Fernando IV concede a la misma persona la martiniega de Cornejo (Ibíd., XIV, 203). En cuanto a Alfonso X, es mencionado por la concesión a Laredo de usu carta seellada con su seello de çera pendiente» en la que les exime del yantar; el recuerdo aquí no es producto de la memoria oral sino de privilegios celosamente custodiados por sus destinatarios (Ibid., XIV, 328). 
cias que se adivinan en el momento de la redacción del Becerro debieron existir con anterioridad y ser el puente de unión entre la realidad inicial y la existente a mediados del siglo XIV.

Las concesiones documentadas son escasas para el yantar y la fonsadera (aproximadamente representan el 1\% de las existencias) debido a la naturaleza de una y otra carga, mayoritariamente señorial y casi exclusivamente real respectivamente. Sin embargo, si comparamos las concesiones del yantar con los yantares reales existentes fuera del realengo representan un porcentaje bastante elevado si tenemos en cuenta que sólo se señalan las concesiones recientes. En la martiniega, las concesiones son más importantes suponiendo el $6,24 \%$. Esto, unido al mayor peso de esta carga, hace especialmente significativo el estudio de este detalle.

De las concesiones de martiniega, aproximadamente una cuarta parte de las mismas van destinadas a personas que detentan la jurisdicción señorial del lugar correspondiente, mientras una octava son resultado de cambios entre el rey y particulares. De las primeras se aprovechan personas que tienen una especial relación con Pedro I en los primeros años de su reinado (Juan Fernández de Hinestrosa) o que ocupan cargos en la administración territorial (Pedro Fernández de Velasco, prestamero, o Sancho Ruiz de Villegas, merino, también se beneficia su hijo Juan Rodríguez de Villegas Pan y Agua), miembros de la alta aristocracia (Fernando Rodríguez de Villalobos), monasterios y catedrales (catedral de Burgos, monasterio de San Isidro de Dueñas) y personas de menor relieve social (Pedro Ruiz, Teresa Ortiz, etc.). Las concesiones de rentas a los señores jurisdiccionales serían las que tendrían más posibilidades de consolidarse. De hecho contrasta el elevado porcentaje de concesiones a particulares ' con la escasa detentación por éstos de rentas en las que no se menciona la concesión. Los señores jurisdiccionales intentarían impedir que personas extrañas consolidasen derechos en sus dominios. En algún caso (el citado de Sancho Sánchez de Velasco) personas que no detentan la jurisdicción transmiten a sus herederos la concesión, pero todo hace pensar que esto no sería habitual. Es sintomático en este sentido que Pedro Fernández de Velasco lleve una martiniega que antes poseía Diego López de Haro ", sin que nada haga pensar en una herencia. En definitiva el peso de las concesiones reales junto al elevado número de las martiniegas señoriales y el muy escaso de las particulares en las que no consta la concesión ni se detenta la jurisdicción señorial nos hace pensar que si bien las concesiones cogían un

' Consideramos como tales a aquéllos que no tienen jurisdicción en los lugares en los que perciben determinadas rentas; sin embargo, todas las concesiones de rentas, independientemente de que las reciba el señor o alguna persona ajena al lugar, las catalogamos como concesiones a particulares.

${ }^{8}$ Becerro (XV, 10). 
abanico amplio en el que los señores eran minoría, la consolidación de las mismas era más fácil cuando se detentaban atribuciones jurisdiccionales. No debemos olvidar para valorar este detalle que aquéllos que reciben rentas en sus señoríos también las reciben fuera de ellos. Así, Juan Fernández de Hinestrosa, Fernando Rodríguez de Villalobos o la catedral de Burgos, por citar a los que acumulan más concesiones?.

Una razón adicional explica por qué se consolidaron peor aquellas concesiones que no se daban a los detendadores de la jurisdicción señorial. Las concesiones y detentaciones de rentas por particulares tenían un carácter marcadamente coyuntural. Por ejemplo, el infante Tello, hijo de Alfonso XI, acumula más de la mitad de las martiniegas detentadas por particulares y asimismo es uno de los que más concesiones recibe (las primeras sin duda son concesiones en los que no consta este extremo, pues su elevado número hace difícil pensar en alguna herencia). Tanto la suerte de Tello, como la de Juan Fernández de Hinestrosa o la de Juan Alfonso de Alburquerque haría aleatorias estas concesiones y detentaciones.

De todos modos, las concesiones reales constituirían simplemente un modo de transmisión de estas rentas a los señores. Es ilógico pensar que se aprovecharan de ella personas que no tuvieran una especial relación con el rey. Por ello, la mayor parte de los señores debieron usar otro procedimiento no menos importante que el señalado: la consolidación de situaciones mantenidas durante un tiempo suficiente ${ }^{10}$.

Hemos mencionado la violencia o, quizás de un modo más suave, situaciones de fuerza como forma de consolidación de derechos. Esta, como hemos señalado, debió tener una gran importancia en la configuración de las realidades que estudiamos. Los simples mecanismos legales no explicarían con seguridad todas las situaciones si conociesemos los pormenores. La violencia explícita

9 Juan Fernández de Hinestrosa: Becerro, XI, 2, 3, 5, 12, 14 -señor del lugar- y 15; Fernando Rodríguez de Villalobos: Ibid., XI, 23, 24, 26, 29 -divisero de la behetría-, 38, 39, 41, 51 -uno de los señores-y 99); catedral y obispo de Burgos: Ibid., XI, 66, 68 -en ambos es señor- y 75).

${ }^{10}$ En el Becerro sólo aparecen ejemplos dudosos sobre la apropiación señorial sin concesión real. En Villanueva de Odra, la martiniega es un derecho real pero «estos maravedis que los lievan los sennores que son naturales del dicho lugar»; en Carazo, posiblemente Domingo Pérez de Bañuelos había recibido una concesión regia en esta carga, pues es improbable que don Nuño, señor de Vizcaya, permitiera intromisiones en un lugar bajo su dominio (VI, 48 y XV, 6). En varios casos concentrados en la merindad de Santo Domingo de Silos, los monasterios de Silos y, sobre todo, Arlanza reciben el yantar del rey o el de éste y el de la reina y/o el adelantado sin que se especifique la existencia de ninguna concesión ni se mencionen dichos yantares entre los derechos reales sino entre los señoriales (XV, 60, 61, 62, 66, 69, 70, 74, 84 y 127). De cualquier modo, estos ejemplos se prestan a diversas interpretaciones. 
aflora en ocasiones como medio de alterar las realidades rentísticas o fiscales. Sin embargo, lo que llama la atención es la escasez de ejemplos en que se menciona el cobro de rentas sin que se ajusten a la costumbre y como hechos de fuerza ". De hecho, salvo la fonsadera, que tiene unas características especiales, las referencias explícitas a este fenómeno son muy escasas. Los señores cobran un yantar y dos martiniegas sin derecho y el merino tres yantares ${ }^{12}$. Son ejemplos insignificantes. En ningún caso se señala explícitamente que alguna renta real sea percibida por los señores. Es posible que esto signifique que los derechos señoriales en el campo que estudiamos estaban asentados desde hacía tiempo y no se habían producido transformaciones recientes mediante esta vía. La violencia aparece en todo caso de modo más implícito: aquellos señores que tienen más capacidad de ejercer violencia detentan más derechos. Es este mecanismo el que parece explicar las diferencias de carácter jurisdiccional.

Si lo que acabamos de decir es válido para la martiniega y el yantar, la fonsadera ofrece otro perfil. La realeza no consideraba permanentes determinadas concesiones de exenciones cuando determinadas circunstancias aconsejaban lo contrario. En este sentido, la cerca de Algeciras aparece como primera causa del pago de fonsadera por lugares que disfrutaban de su exención ${ }^{13}$. En algunos casos se señala simplemente que se cobra en contra de la costumbre, pero todo hace pensar que se debería a la causa antedicha. En un 8,30\% de las existencias, su cobro se realiza pese a una situación de exención explícita o de hecho. La misma naturaleza de la fonsadera posibilitaba esta situación. Aunque en algún lugar pudo llegar a ser una carga anual, en su origen y a mediados del siglo XIV en gran medida era una carga aleatoria en función de las condiciones militares.

"Sobre el particular no debemos olvidar que es la violencia la causa que ofrece Claudio SÁNCHEZ ALBORNOZ para explicar la evolución de las behetrías y más concretamente los derechos detentados por los Lara en esta jurisdicción (Las bebetrias y la encomendación en Asturias, León y Castilla, "Viejos y nuevos estudios sobre las instituciones medievales españolas», Madrid, 1976, pp. 138-139). La violencia en la medida que supone la transgresión de la costumbre sólo se recuerda un tiempo limitado, hasta que la nueva situación se consolida y engendra una nueva costumbre en torno a la cual disputarán nuevamente señores y campesinos.

$12 \mathrm{X}, 47,122$ y $123 ; \mathrm{XI}, 1$ y $17 ; \mathrm{XV}, 36$.

${ }_{13}$ El cerco de Algeciras fue largo, se prolongó durante año y medio entre 1342 y 1344 , y costoso, de hecho propició el inicio del cobro de la alcabala, unas de las rentas más lucrativas de la hacienda castellana bajomedieval. No es extraño, por tanto, que incidiera en el cobro de la fonsadera (Juan TORRES FONTES, Julio GONZÁleZ, Salvador de MOXó y María Paz ALONSO ROMERO, La expansión militar y mediterránea (c. 1212-c. 1350). La Corona de Castilla, en «Historia de España», dirigida por R. Menéndez Pidal, XIII-I, Madrid, 1990, pp. $408-415$. 
Por tanto, ciertas condiciones difíciles podían cambiar la situación creada a la vez que ciertas costumbres, sobre todo si no había exención explícita, creaban derecho más difícilmente. En cualquier caso, con o sin exención explícita, las condiciones mandaban y permitían alterar la situación ${ }^{14}$. De todos modos, dado que no se llegó a cobrar de modo general, las alteraciones de la costumbre en los lugares señalados no tuvieron sino una importancia marginal en los ingresos reales. Además, las transgresiones de privilegios estaban limitadas prácticamente al abadengo.

Podemos señalar, por tanto, que a mediados del siglo XIV los derechos de los perceptores sobre las cargas que estudiamos parecen estar asentados desde hace bastante tiempo, pues los cambios en las mismas son limitados, especialmente los que significan una apropiación violenta. En ningún caso se posterga de modo claro e inequívoco por este mecanismo el derecho de ningún otro perceptor. A juzgar por los datos del Becerro, las concesiones reales (muchas de ellas llamadas a no consolidarse) parecen jugar un papel más importante que la simple violencia, aunque las diferencias de carácter jurisdiccional que veremos en otro apartado nos permiten afirmar que los derechos detentados están en relación directa con la capacidad de utilizarla.

\section{LA MARTINIEGA}

La martiniega destaca en el Becerro por su importancia. Las existencias casi triplican las exenciones. Aproximadamente se da en dos de cada tres lugares. Esto hace que después de la renta solariega, prácticamente omnipresente (simplemente falta en algunos lugares de behetría por claro privilegio y en algunos otros no sabemos si por laguna informativa o inexistencia), sea la carga más frecuente.

La martiniega aparece claramente diferenciada de los pagos de la renta solariega en San Martín. Tanto en el realengo como en las demás jurisdicciones, se presenta al margen de los pechos de carácter territorial, se paguen o no en esta fecha. Ni siquiera en el realengo, pese al carácter primigeniamente público

14 En Obarenes, «quando el Rey don Alfonso se echo sobre Algezira enbio demandar a los del dicho logar que pagasen fonsadera e moneda e los del dicho logar enviaron mostrar al . Rey los previlleios que tenian de los Reyes e confirmados del, que se contenia que eran quitos, e quando los el Rey vio mando que la non pagasen» (Becerro, XIV, 38). Este caso es un ejemplo aislado y son numerosos los ejemplos en los que se satisface la fonsadera pese a que existen privilegios. 
de la martiniega, se llega a fundir ésta con la renta solariega ". Al menos, por tanto, para la Castilla de las merindades (esto merecería un estudio más detallado) ambas obligaciones aparecen clara y nítidamente diferenciadas.

La martiniega es cobrada por el rey de modo claramente mayoritario ${ }^{16}$. Aparece como perceptor exclusivo en casi el $42,51 \%$ de los casos, es decir, en más de dos de cada cinco. Además, participa en el $9,47 \%$ con otros perceptores. Todo esto hace que en más del $50 \%$ de los casos, el rey se encuentre entre los recipiendarios de esta renta. Normalmente, la parte real es superior a la de los demás, siendo raro que no reciba al menos la mitad".

Los señores también participan en el cobro de esta carga en una proporción estimable. Son perceptores exclusivos en aproximadamente un tercio de los casos $(31,32 \%)$ y participan con otros recipiendarios en un $12,37 \%$. Su participación en esta carga se aproxima al $44 \%$, muy importante, pero claramente inferior a la real.

El rey y los señores aparecen conjuntamente en la percepción de esta carga en algo menos del $8 \%(7,64)$ siendo los dos únicos perceptores en un $4,30 \%$.

Los restantes perceptores tienen una importancia considerablemente inferior, dados los porcentajes que acabamos de señalar. Si sumamos los casos en que el monarca y los señores reciben la martiniega de modo exclusivo y les añadimos aquéllos en que la reciben conjuntamente sin participación alguna de

1s Salustiano Moreta, Rentas monásticas de Castilla. Problemas de método, Salamanca, 1974 , p. 104) señala que pese a que a veces se confunden la infurción y la martiniega, wen muchos lugares se trata de rentas y fiscalidades distintas, diferenciadas claramente tanto en el Libro de Cuentas como en el Becerro de las Behetrías». Por lo que respecta a nosotros, pensamos que esta última fuente siempre presenta nítidamente diferenciadas ambas cargas, siendo numerosísimos los ejemplos. La martiniega se paga en San Martín pero aparece separada de otros pagos solariegos que pueden satisfacerse en esta fecha, lo que frecuentemente sucede, pero a los que nunca se les da esta denominación.

16 Una situación parecida ofrece la Tierra de Campos: el rey es el perceptor exclusivo de la martiniega en ciento veinticuatro ocasiones y los señores, en setenta; ambos la comparten ciento cuarenta y tres veces (Angel Vaca, Ibid., p. 356); excepcional y muy interesante es el ejemplo que ofrece la merindad de Burgos-Ubierna, en la que la catedral de Burgos se presenta como la mayor perceptora seguida de los señores territoriales, ocupando el rey una posición claramente subordinada (Ignacio Alvarez Borge, Ibid., pp. 114-115).

17 De excepcional puede considerarse que el rey reciba menos que otros perceptores: en Santoyo (XI, 10) sólo recibe diez de los doscientos cuarenta y seis maravedíes de que consta la martiniega, pero la mayor parte va al castillo de Burgos, constituyendo una renta real indirecta; en Contreras $(\mathrm{XV}, 4)$ también recibe sólo una pequeña parte debido a la concesión que Alfonso XI realizó a Juan Manso de Valladolid y a su padre, a lo que se añade la existencia de otros perceptores. 
ningún otro perceptor nos situamos aproximadamente en el $80 \%(78,13)$, cuatro sobre cinco casos.

Las razones cuantitativas, por tanto, de lo que acabamos de señalar son claras. Hay otras de no menor peso que afectan igualmente a las restantes cargas que estudiamos: los restantes perceptores son mayoritariamente oficiales reales, fortalezas o personas que deben su participación a una concesión real. A éstos sólo hay que añadir a otros que sin ser señores ni contar con ninguna positiva merced regia detentan ciertos derechos. En los dos primeros supuestos (oficiales reales y fortalezas), el rey puede considerarse perceptor indirecto, pues la carga sirve para completar el salario de sus oficiales o para subvenir a las necesidades de sus fortalezas ${ }^{18}$.

Veamos los porcentajes de participación de los restantes perceptores ${ }^{19}$

\begin{tabular}{|c|c|c|}
\hline Perceptor & Exclus & Compart \\
\hline Adelantado & - & 9,04 \\
\hline Merino & - & 1,08 \\
\hline Particular & 1,51 & 1,72 \\
\hline Conces. partic. & 4,30 & 1,83 \\
\hline Castillo & 1,29 & 3.01 \\
\hline Prestamero & 1,18 & 0,54 \\
\hline Reina & 0,54 & - \\
\hline
\end{tabular}

La participación exclusiva de todos estos perceptores no llega al 10\%, y sólo disfrutan, por tanto, de un peso residual. En su gran mayoría, conllevan una renta real indirecta, lo que aumenta aún más el peso real de la realeza en la percepción de esta renta.

Predominio real pero participación considerable de los señores definen, de este modo, el reparto de la martiniega.

16 En algunas ocasiones esto aparece con meridiana claridad. Por ejemplo, en Itero de la Vega los ciento veinte maravedíses de la martiniega le corresponde cobrarlos al rey, pero «Estos maravedis lievalos el castellero de Burgos»; lo mismo sucede en Castrillo de Murcia o Valbuena de Pisuerga (XI, 7, 8 y 9).

19 Además de los perceptores señalados en el cuadro aparecen los siguientes, con un peso absolutamente residual: los naturales de las behetrías, un caso de percepción exclusiva (la recibe un natural solamente) y otro compartida; castellanos, tres de compartida; retenencia de castillo, un caso de exclusiva; orden y monasterio (sin concretar más en ninguno de los dos casos), uno de compartida en cada supuesto; y señor de la tierra, uno de compartida. En un caso (no cuantificado en el cuadro) no queda claro si el destinatario es el prestamero o se trata de una concesión particular. 


\section{LA FONSADERA}

La fonsadera ofrece un perfil muy diferente del que presentan la martiniega y, como veremos, el yantar. Su peso es muy inferior al de la primera carga citada y muy similar al de la segunda. Aparece en alrededor del $17 \%$ de los casos ${ }^{20}$. No es extraño, consiguientemente, que las exenciones explícitas (casi el 42\%) dupliquen con creces las existencias.

La fonsadera presenta un perfil nítido en relación con sus perceptores. Al contrario de lo que sucede para la martiniega o el yantar, salvo uno de ellos los demás tienen un peso absolutamente residual. El rey recibe de modo exclusivo la fonsadera en un $92,83 \%$ de los casos, compartiéndola con los señores en un $1,13 \%{ }^{21}$. Frente a esto, los señores sólo la obtienen del primer modo señalado en un 3,40\%. El rey es especialmente cuidadoso en la concesión de esta carga, lo que sólo hace en dos ocasiones. En un caso la percibe el castillo de Lara, y en tres, el prestamero. Ni el adelantado ni los merinos detentan derechos sobre la fonsadera. Especialmente sintomático de lo que acabamos de decir es que no aparezcan ningún perceptor particular que no sea jurisdiccional del lugar en cuestión sin que medie explícitamente una concesión regia.

El perfil característico de la fonsadera se debe a su naturaleza. Es una carga ligada a la guerra y la monarquía castellanoleonesa protege especialmente sus atribuciones en este ámbito, dentro de lo que constituye una constante de la edad media peninsular. Las concesiones de la fonsadera no tenían sólo una vertiente fiscal (como sucede para la martiniega), sino también otra política no menos importante. Por tanto, la especial hegemonía que ejerce en la edad media la monarquía castellana explica el casi monopolio que pudo mantener en el cobro de una carga ligada a la guerra como era la fonsadera, que se integra en contadísimas ocasiones dentro de los derechos señoriales.

\section{EL YANTAR}

El yantar tiene una incidencia prácticamente idéntica a la de la fonsadera: aparece en doscientas cuarenta y nueve ocasiones $(16 \%)^{22}$, algunas menos que

20 Este porcentaje es muy similar al existente en la Tierra de Campos (17,55\%) o la merindad de Burgos-Ubierna (22\%) (Angel VACA, lbid., p. 266; Ignacio ALVAREZ BORGE, Ibid., p. 108).

${ }^{21}$ Una situación idéntica se da en las restantes merindades: Angel VACA, Ibid., pp. 266-269; Ignacio ALVAREZ BORGE, Ibid., p. 108.

${ }^{22}$ En la Tierra de Campos llegaba al $27 \%$ mientras en Burgos-Ubierna no alcanzaba el 5\% (Angel VACA, Ibid., p. 364; Ignacio Alvarez Borge. Ibid., p. 91). 
esta última. Al igual que la martiniega o la fonsadera presenta un perfil específico en relación con sus perceptores. El yantar es la única carga de las tres en que los señores aparecen como recipiendarios mayoritarios ${ }^{23}$. Los señores obtienen esta carga de modo exclusivo en un $65,46 \%$, que triplica con creces el $19,68 \%$ que corresponde al rey. La diferencia es aún considerablemente mayor si se tiene en cuenta que, al contrario de lo que sucede con la martiniega o la fonsadera, dos tercios de los yantares percibidos por el rey los obtiene en el realengo y, por ello, no tanto en su calidad de rey como en la de señor jurisdiccional ${ }^{24}$. Si tenemos en cuenta este detalle (que nos hace pensar en el origen señorial de los derechos que el monarca tiene sobre esta carga en el realengo) los porcentajes anteriores son respectivamente del 78,71 y del 6,43 (incluido en este apartado una percepción real del yantar en un condominio abandego/realengo) ${ }^{25}$.

Si sumamos los porcentajes en que el rey y los señores son perceptores exclusivos del yantar nos situamos en el $85,14 \%$, a lo que hay que sumar el $1,61 \%$ en que lo cobran conjuntamente sin participación de terceros. A esto hay que unir el $2 \%$ de participación real con otros perceptores (incluidos los señores); éstos en idéntica situación no alcanzan el $1 \%$.

Por tanto, y al contrario de lo que sucede con la fonsadera, pero en un grado muy similar aunque algo inferior, el yantar es una carga marcadamente señorial, hasta el punto de que este carácter predomina incluso en los derechos que posee en este campo la monarquía. Esto es aún más llamativo si se tiene en cuenta que las concesiones regias sobre esta carga no son numerosas (tres casos sobre doscientos cuarenta y nueve), los que nos hace pensar que la situación que nos presenta el Becerro estaba asentada desde hace bastante tiempo, caso de que las concesiones reales hubieran sido abundantes en algún momento, o responde a una situación originaria, es decir, que el yantar fue siempre y fundamentalmente una carga de marcado carácter señorial.

El espectro de los perceptores del yantar es mayor que el de la fonsadera, lo cual es normal dado el carácter de ésta y su ligazón con uno de los aspectos monopolizados por el estado. Perciben el yantar en alguna ocasión el adelanta-

${ }^{23}$ En Burgos-Ubierna, en los escasos ejemplos existentes, siempre la recibe el señor correspondiente (Ignacio AlVAREZ BORGE, Ibid., p. 91).

24. Algo similar sucede en la Tierra de Campos: sobre cincuenta y seis yantares reales (que suponen una cantidad limitada frente a los ciento diez señoriales), cuarenta se dan en el realengo (Angel VACA, Ibid., p. 371).

2) Esto exigiría matizar la opinión de Miguel Angel LADERO QUESADA, Ingreso, gasto y politica fiscal de la Corona de Castilla. Desde Alfonso X a Enrique III (1252-1406), «El siglo XV en Castilla. Fuentes de renta y política fiscal», Barcelona, 1982, p. 16, de que «En la época que nos ocupa la monarquía procura generalizar las obligaciones de fonsadera y yantar como derechos irrenunciables del reyn. 
do (siete, una de ellas de modo exclusivo), el merino (once y cinco respectivamente), el prestamero (dos y una), el tenente del castillo de Castrojeriz (una vez de modo exclusivo), el señor de la tierra (una vez de modo exclusivo) a lo que hay que unir tres casos de concesión real y cuatro en que lo cobran particulares (en ambos supuestos de modo exclusivo). En cuatro ocasiones lo recibe la reina (una en el realengo como consorte real y tres de modo exclusivo sobre sus dependientes jurisdiccionales) y en dos los diviseros, que no podemos considerar estrictamente señores.

Todos estos perceptores conjuntamente no llegan al $15 \%$ de participación en el yantar. El que los obtiene en mayor número, el merino, sólo participa en un 4,42\%, representando sólo el $2,01 \%$ aquellos casos en los que es único recipiendario. Aunque la participación de este colectivo es mayor que en la fonsadera, tiene un peso bastante limitado.

\section{LAS JURISDICCIONES}

Cada carga tiene su personalidad particular, pero igualmente la tiene cada jurisdicción. Es más, las características señaladas para la martiniega, la fonsadera y el yantar están muy influidas por el distinto perfil que presentan las distintas jurisdicciones. Hemos dejado a un lado los condominios ${ }^{26}$ y la encartación, jurisdicción de escaso peso y por tanto pequeña importancia. Esto no resta consistencia a nuestras conclusiones, pues la behetría, el abadengo el solariego y el realengo conjuntamente vienen a representar algo menos de los dos tercios de los lugares estudiados. Por otro lado, las distintas jurisdicciones suelen presentar las mismas características cuando se reparten un lugar con alguna otra ${ }^{27}$.

Veamos en que medida porcentual participan el rey y los señores de un modo exclusivo $(=1)$ y globalmente $(=2)$ en las tres cargas que estudiamos en las distintas jurisdicciones (excluimos del cuadro al realengo pues en el rey y señor se funden en una misma persona) ${ }^{28}$.

${ }_{26}$ Consideramos como tales sólo aquellos lugares que además de estar repartidos entre diversos señores cuentan con diversas jurisdicciones; por tanto, no existen para nosotros los condominios solariegos, abadengos o de behetría, a los que consideramos simplemente lugares de solariego, abadengo o behetría.

27 Angel VACA, Ibid. pp. 243-249.

${ }_{28}$ Angel VACA, Ibid. p. 256, nos presenta un perfil muy similar para su zona de estudio. Sus conclusiones pueden resumirse del modo que sigue: la fonsadera se da sobre todo en el realengo y el abadengo, percibiéndola el rey; la martiniega la obtienen los señores en el solariego, total o parcialmente el rey en la behetría y el rey y los señores en el abadengo; el 


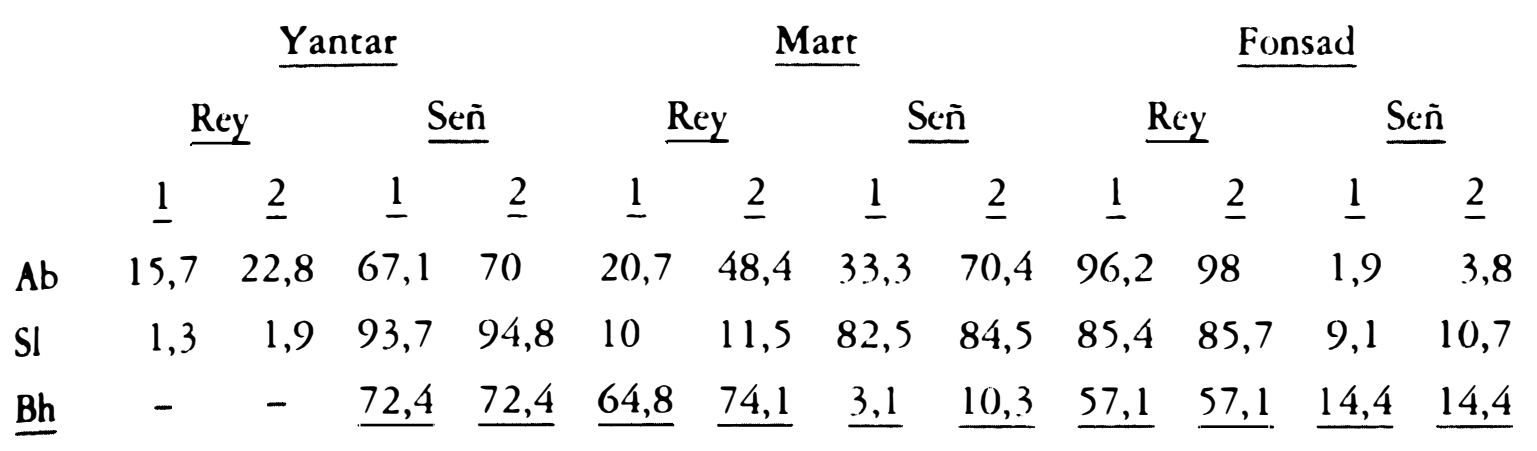

Para que estos porcentajes sean significativos no debemos olvidar que la incidencia de las diversas cargas en cada una de las jurisdicciones es muy diferente, aspecto que matizará o condicionará fuertemente los porcentajes anteriores, no significativos en sí mismos o al menos no en toda su dimensión. En el abadengo es muy frecuente la fonsadera $(37,37 \%)$, mientras la martiniega y el yantar mantienen porcentajes más normales $(56,58$ y 24,91$)$. En el solariego, estas dos últimas cargas tienen un peso no muy alejado del medio $(55,16$ y 17,36$)$, pero la fonsadera se sitúa por debajo $(12,31 \%)^{29}$. En la behetría el yantar es poco importante $(7,94 \%)$ y la fonsadera casi inexistente $(1,91 \%)$, sin embargo tiene una gran importancia la martiniega $(79,45 \%)$. Por tanto, resalta la incidencia de la fonsadera en el abadengo y de la martiniega en la behetría, así como el limitado peso de la fonsadera en el solariego y su casi inexistencia en la behetría. En conjunto, los valores porcentuales del solariego se acercan a los medios con ciertos matices, todo lo contrario de lo que sucede en la behetría; en el abadengo están por encima, salvo para la martiniega.

En cuanto a los perceptores de las cargas que estudiamos, en líneas generales podemos señalar que el solariego se define por la mayor participación señorial y la menor real. Distinto perfil presenta el abadengo: comparado con el solariego, el rey siempre participa en mayor medida y los señores en menor. Además, en esta jurisdicción los porcentajes de participación real generalmente son superiores a la media. En la behetría, el yantar y la fonsadera tienen escasa importancia para definir sus características: la gran relevancia que el rey tiene en esta jurisdicción es debido a que en una carga que se da en el $79,45 \%$, es el

yantar va a a parar a los señores en la behetría y el solariego mientras en el abadengo se lo reparten con el rey.

${ }^{29}$ En algunas ocasiones, aunque con menos frecuencia que en la Tierra de Campos, se alude al caracter privilegiado de esta jurisdicción mediante frases como «non pagan martiniga nin fonsadera porque son solariegos» o «non pagan martiniega porque son solariegos» (Becerro, XII, 49; XV, 15 y 16). Esto contrasta con la incidencia que la martiniega tiene en la jurisdicción solariega, que se acerca a la media; además, aunque la fonsadera se sitúa por debajo, tiene, por ejemplo, mayor peso que en la behetría. Posiblemente estas circunstancias explican las escasas alusiones a este presunto carácter privilegiado del solariego. 
perceptor mayoritario y, lo que es tan importante como esto, los señores tienen un peso residual.

Veamos ahora cada caso separadamente. El solariego es la jurisdicción en que la participación señorial en la percepción de las cargas que estudiamos es mayor. Sólo para la fonsadera es superado por la behetría que en el solariego; en los restantes casos, esta jurisdicción se sitúa por encima de la behetría y del abadengo. La excepción existente es poco significativa, pues la fonsadera es infrecuentísima en la behetría y la participación señorial en ella se limita a un caso que genera un alto porcentaje. Por tanto, la norma general puede decirse que se cumple en su práctica totalidad. La participación señorial exclusiva en el yantar se acerca al $94 \%$, mientras behetría y abadengo rondan el $70 \%$. Pero si aquí la diferencia es llamativa, aún es mayor en la martiniega, donde los porcentajes respectivos de participación señorial exclusiva son del 82.3, 3.1 y 33.3. Esta mayor participación señorial choca con el carácter manifiestamente fiscal, y por tanto real, de la fonsadera, en cuya percepción los señores solariegos participan en una proporción muy limitada aunque es cuatro veces mayor que la de los señores abandegos. Posiblemente, esta realidad se debe al peso militar de este grupo netamente superior al de estos últimos. Es, en todo caso, un aspecto que trasciende a nuestra fuente de estudio.

En el abadengo, los señores también han conseguido detentar derechos importantes. En la martiniega y el yantar la participación señorial supera la media existente en cada carga, aunque esté claramente por debajo del solariego. En cualquier caso no debemos olvidar que la media de la martiniega esconde realidades muy desiguales en cada jurisdicción debido al importante control que de esta carga tiene el rey en la behetría. En el abadengo por tanto, yantar y martiniega tienen un carácter señorial, carácter bastante acusado en el primer caso y relativamente moderado en el segundo. La fonsadera se caracteriza por el práctico monopolio real lo que se produce junto a un peso de esta carga prácticamente dobla la media. El rasgo más característico, por tanto, del abadengo es el importante control que el rey tiene de esta carga y que afecta tanto a sus existencias como a su percepción. La menor participación militar del clero en la guerra aparece como la hipótesis más plausible para explicar esta realidad.

La behetría presenta unas características muy particulares, lo que no es de extrañar en una jurisdicción tan peculiar y, a su vez, tan necesitada de estudios. Los porcentajes del yantar y la fonsadera tienen una importancia secundaria habida cuenta de su escaso peso en esta jurisdicción. De residual puede considerarse la fonsadera y en cuanto al yantar su peso es cuatro veces inferior al que tiene en el abadengo y representa menos de la mitad del que alcanza en el solariego. Son dos cargas de mayoritaria percepción real y señorial respectivamente, como corresponde al carácter de cada una de ellas y como se presentan con grados variables de intensidad en las restantes jurisdicciones. 
Lo que tiene gran importancia para la behetría es la martiniega, pues une a su peso unas características señaladas en cuanto a sus perceptores. Esta carga se da en un 79,45\% en esta jurisdicción, siendo la única en la que se presenta de modo claro por encima de la media. En este aspecto, abadengo, solariego y realengo tienen una relativa homogeneidad, con diferencias muy inferiores a las existentes para la fonsadera y el yantar. Este elevado peso de la martiniega va unido en la behetría a su carácter marcadamente real. El rey es el perceptor exclusivo en dos de cada tres casos y en tres de cada cuatro participa en su cobro. Frente a esto, la participación señorial es practicamente residual ". Es evidente que el rey ha utilizado la especial situación de inestabilidad dominical que al menos originariamente ha tenido la behetría para arrogarse alguna especie de patrocinio que le ha permitido tener importantes derechos sobre esta jurisdicción, en la cual el monarca aparece, en general, dada la frecuencia de la martiniega, como uno de los mayores perceptores. Debemos suponer esta situación como algo heredado y antiguo y, como hipótesis, todo hace pensar en las peculiaridades de la behetría. Responder adecuadamente al planteamiento anterior exigiría ahondar en el estudio de la misma y de la martiniega.

El realengo es una jurisdicción particular en donde la delimitación entre lo señorial y lo estatal no puede hacerse sino a través del estudio de las restantes jurisdicciones. Al unir el rey el doble carácter de monarca y señor jurisdiccional, la separación realizada para las demás jurisdicciones en lo que atañe a los perceptores no tiene sentido aquí. Merece, sin embargo, que señalemos algunos detalles. La peculiaridad más resaltable en relación con las cargas que son objeto de estudio es la gran importancia que tiene el yantar $(50,68 \%$ de existencias), lo que nos hace pensar que el gran desarrollo que esta carga tiene en el siglo XIII es algo particular de esta jurisdicción y en mucha menor medida de las restantes ". Las demás cargas ofrecen porcentajes más normales. La martiniega tiene un peso en el realengo muy similar al que posee en el solariego o el abadengo; sin embargo, la fonsadera es mucho más frecuente que en el solariego (más del doble), aunque mucho menos que en el abadengo. En el realengo, el rey aparece como mayoritario perceptor de estas cargas: monopoliza la fonsadera y aparece como único perceptor del yantar y de la martiniega en un $83,78 \%$ y un $86,67 \%$.

* Claudio SÁNCHEZ AlboRnoz (Las bebetrias, pp. 146-147) señala sobre la martiniega que «Su cobranza por el señor de la behetría era excepción no muy frecuente y consecuencia de una merced del soberano o de una violencia del hidalgo elegido por patrono. En muchos casos puede comprobarse la concesión previa del monarca, podemos, por tanto, considerar expresa o tácita, remota o cercana, pero general e indispensable. A veces también puede documentarse el atropello del señor en la percepción de este canon».

"Sobre la evolución de esta carga en el realengo, Julián CLEMENTE RAMOS, Estructuras señoriales castellano-leonesas: el Realengo (siglos XI-XIII), Cáceres, 1989, pp. 213-215. 


\section{CONCLUSIONES}

Cada una de las cargas estudiadas tiene un perfil característico que la separa de las restantes. Junto a esto hay que tener en cuenta que las diversas jurisdicciones también ofrecen ciertas particularidades que condicionan, en algún caso fuertemente, el modo en que se presentan dentro de ellas. Cargas y jurisdicciones tiene, por tanto, peculiaridades que no podemos olvidar.

Quizás la carga que ofrece unos rasgos más marcados, que se manifiestan a su vez con total claridad en todas las jurisdicciones, es la fonsadera. Esta obligación tiene un carácter marcadamente fiscal. El rey es el receptor mayoritario, por no decir casi el único. Hay un gran control sobre sus concesiones, que son muy limitadas comparadas con los derechos regios en este campo. Sin lugar a dudas es este un rasgo que entra en relación con las características del estado feudal castellanoleonés, en el que la hegemonía real es muy clara. El estado protege sus prerrogativas en un terreno en el que la vertiente económica es secundaria frente a la política. La vinculación de la fonsadera con la guerra es un elemento que explica sus peculiaridades.

El yantar, al contrario que la fonsadera pero de modo menos marcado, es mayoritaria y claramente un derecho señorial. Los yantares regios son limitados y además, lo que es aún más importante, se obtienen sobre todo en el realengo. El carácter señorial se mantiene en las distintas jurisdicciones. Las diferencias son, sobre todo, de intensidad. Mientras en el solariego roza el monopolio, en la behetría y el abadengo se mantiene en porcentajes claramente inferiores.

Distinto panorama ofrece la martiniega. Esta conserva todavía en la Castilla de las merindades un carácter en gran medida fiscal aunque los señores poseen sobre ella bastantes derechos. Es la carga en que los derechos señoriales y reales están más igualados. Este rasgo general no señala, sin embargo, más que una parte de la realidad. La martiniega es una carga mayoritariamente real debido a los derechos que sobre la misma mantiene el rey en la behetría, jurisdicción en la que se da en un porcentaje elevadísimo. Por ello, la martiniega la obtienen fundamentalmente los señores solariegos y abadengos y, sobre todo, el rey. En este sentido, la martiniega presenta un perfil bastante variado en relación con las diversas jurisdicciones.

De todo lo dicho se infiere el carácter casi exclusivamente fiscal de la fonsadera, claramente señorial del yantar y oscilante, en función de las jurisdicciones, de la martiniega.

Ya hemos aludido a la distinta personalidad de las diversas jurisdicciones. Cada una de ellas presenta un modelo diferente. En general, en el solariego los derechos señoriales están más desarrollados. Estos son predominantes tanto para el yantar como para la martiniega; sólo, para la fonsadera los derechos 
regios, como en todas las jurisdicciones, son mucho más importantes. En el abadengo, los derechos señoriales son importantes, pero netamente inferiores a los existentes en la anterior jurisdicción. También en ella yantar y martiniega son derechos señoriales, pero mientras en el solariego esto llega casi a la exclusividad en el abadengo se mantiene en límites muchos más modestos. Con todo, hay que ir a la behetría para ver una jurisdicción en la que los derechos reales sobre las cargas estudiadas son más importantes que los señoriales. La fonsadera y el yantar tienen poca importancia al ser infrecuentes. En cuanto a la martiniega, el rey es el perceptor mayoritario frente a los casi inexistentes derechos señoriales.

Como hipótesis podemos señalar que el poder militar de los señores solariegos y la inestabilidad jurisdiccional de la behetría aparecen como dos explicaciones posibles de las características señaladas. Ambas jurisdicciones se sitúan alrededor del abadengo, que en este aspecto se ubica en valores medios.

\section{RÉSUMÉ}

L'analyse des similitudes, des différences et des frontières qui existent entre la fiscalité royale et le revenu féodal n'a pas encore éveillé toute l'attention qu'elle mérite. C'est la raison pour laquelle des apports, comme ceus que nous offre $C$. Sánchez Albornoz, sont encore en vigueur plus de soixante-dix ans après. Le Becerro de las Bebetrias (Livre des bienfaisances), grâce à la profusion d'informations qui concernent aussi bien tout ce qui est en rapport avec la fiscalité comme ce qui traite des impôts seigneuriaux, est une source idéale pour montrer un échantillonnage sur ce thème, bien que ces renseignements se limitent au XIV ${ }^{\text {ther }}$ siècle.

Nous avos choisi trois charges en raison de leur relation avec les prérogatives étatiques (fonsadera: ancien tribut pour les dépenses de guerre), leur profonde signification seigneuriale (el yantar: impôt payé en espèces au seigneur de passage: pain et plat de feves ou de lentilles, généralement), ou pour leur généralisation (martiniega: impôt payé pour la Saint Martin). Les particularités très apparentes de chacune d'elles ne peuvent pas être séparées de celles que présentent les différentes juridictions. L'ancien tribut pour les dépenses de guerre, la fonsadera, est une charge typiquement de l'état, tout à fait indépendante de la juridiction. La martiniega, cet impôt payé pour la Saint Martin, ce sont les seigneurs qui la reçoivent, sauf dans le cas de la "behetría", -c'est-à-dire dans le cas d'un village qui n'a pas de seigneur et dont les habitants, par ce fait, peuvent élire qui bon leur semble- où c'est alors le roi qui le perçoit et, de ce fait, en devient un des principaux percepteurs. L'impôt sur la nourriture, el yantar, a un caractère tout à fait seigneurial: le roi le perçoit principalement par le biais du patrimoine royal. Quant aux juridictions, et en tenant compte des charges déjà mentionnées, le contrôle de seigneurs terriens et, en moindre 
mesure, des abbayes sur ceux qui en dépendent est largement supérieur à celui qui existe dans le cas de la "bienfaisance", la behetria, cas dans lequel le roi détourne de substantiels revenus.

\section{SUMMARY}

The analysis of the similarities, the differences and the boundaries that exist between the royal tax system and the feudal incomes has not awakened yet all the attention that it deserves. It is the reason why the contributions like those offered by $C$. Sánchez Albornoz are, seventy years later, still in use. The Becerro de las Behetrias (Record Book of Charity), thanks to its abundant information about all what is related with the tax system and with seigniorial taxes, is an ideal source to present a collection of samples on this topic, even if the information is limited to the XIV"th century.

We have chosen three charges because of their relation with the state prerogatives (la fonsadera: old tax destinde to war expenditures), because of their profound seigniorial meaning (el yantar: tax payed in cash to the visiting lord: bread and beans or lentils, normally), or for their generalisation (la martiniega: tax payed for Saint Martin). The noticeable particularities of each of them cannot be separated from those presented by the different jurisdictions. The old tribute for war expenditures, the fonsadera, is a typically state charge, totally independent from the jurisdiction. The martiniega, a tax payed at the moment for Saint Martin, is perceived by the landlords, except for the behetria -which means that in a village without a landlord, the inhabitants are allowed to elect the person they prefer- where it is the king who perceives it and, consequently, becomes one of the main tax collectors. The tax on food, el yantar, is totally seigniorial: the king perceives it basically through royal patrimony. As far as jurisdictions are concerned, and taking into account the changes already mentioned, the control of the abbeys on those who depend on it is largely more important than the one existing in the case of charity, behetria, since in this case the king diverts substantial incomes. 